\title{
Integration of Ergonomic Aspects into Lot-sizing Model of the Production Line Supply Process Based on Relaxation Allowance and Maximum Endurance Time
}

\author{
Sezen Korkulu¹, Krisztián Bóna ${ }^{1 *}$ \\ 1 Department of Material Handling and Logistics Systems, Faculty of Transportation and Vehicle Engineering, Budapest \\ University of Technology and Economics, Műegyetem rkp. 3., H-1111 Budapest, Hungary \\ ${ }^{*}$ Corresponding author, e-mail: bona.krisztian@kjk.bme.hu
}

Received: 31 January 2022, Accepted: 31 January 2022, Published online: 08 February 2022

\begin{abstract}
The maximum endurance time is a key parameter for the estimation of relaxation allowance and rest time. Recently, researchers have started to investigate and integrate particularly economic aspects of sustainability as well as environmental sustainability dimensions in intralogistics systems, and only a few contributions studied the social aspect of sustainability. Therefore, the aim of the paper is the extension and development of a new cost model based on relaxation allowance and endurance time. The effects of endurance time and relaxation allowance on the total cost of logistics operation were investigated. The developed new model considered the maximum endurance time for calculation of rest time necessary for different quantities of handled items and item weights. The results of comparison with the total cost of maximum lifting and carrying ( $25 \mathrm{~kg}$ ) limit for two-handed lifting show that the percentage savings achieved with the implementation of our new model from using ergonomic rest time and maximum endurance time was equal to $43.2 \%$ in the total cost of production line supply process.
\end{abstract}

Keywords

ergonomics, manual material handling, production line supply, endurance time, relaxation allowance, social sustainability

\section{Introduction}

Many researchers have investigated economic and environmental sustainability of intralogistics systems (Cunha et al., 2018; Ghare and Schrader, 1963; Goyal, 1985; Hadley and Whitin, 1963; Rezaei, 2014; Safaeian et al., 2019; Salameh and Jaber, 2000; Tiwari et al., 2018; Wangsa and Wee, 2018; Zhao et al., 2004) and only a few contributions have been made for social sustainability (Ciccullo et al., 2018). The work-related musculoskeletal disorders and work-related back disorders are the most common occupational disorders that cause lost or restricted work time. It is crucial to prevent WRMDs to promote economic and social sustainability. According to the last report of the EU-OSHA (2017), work-related musculoskeletal disorders are one of the most crucial reasons for death in the EU-28 proportion (14.66\%) and the World proportion (14.96\%). The maximum endurance time was a key parameter for estimating recovery times and quantifying muscular fatigue to prevent work-related musculoskeletal disorders. The endurance time of muscle force is the maximum time of holding force until the pain or fatigue occurs (Eksioglu, 2011). Several researchers have investigated that the relaxation allowance or rest time allowing the recovery from muscular fatigue can be estimated from the endurance time of a muscular force (Corlett and Manenica, 1980; Rohmert, 1960; 1973; Rohmert et al., 1986; Rose et al., 2001). The constituted rest time and time standards were provided with an opportunity to increase the productivity of the workforce and lower the cost of a company. Consequently, the correct establishment of rest time, safe work design, and precise rest allowance for muscular fatigue must be considered in cycle times. In the literature, there can be found a significant number of general and specific muscle group endurance time studies. Rohmert (1960) developed an exponential model for endurance time, and the endurance limit was $15 \%$ fMVC which means that forces till 15\% fMVC can be held without tiring. It was a general model and valid for all muscle groups and not dependent on a worker or task parameters. 
Rohmert et al. (1986) developed endurance time models for specific muscle groups (shoulder, elbow, back, and hand). Corlett and Manenica (1980) have investigated the relationship between endurance time and relative force for the static pull and static torque. Rose et al. (2001) investigated endurance time, pain, and resumption time for fully flexed postures. They found that endurance times in fully flexed postures differ little from those in more common postures. Therefore, the results showed that fully flexed postures might be assessed by more general prediction models for endurance. Garg et al. (2002) studied endurance times for different shoulder postures, and their model does not have the endurance limit.

In the literature, there is a few number of studies found that consider both ergonomics and inventory management (Korkulu and Bóna, 2019). Battini et al. (2011) investigated and analyzed the relationship between ergonomics and assembly system design techniques. Battini et al. (2015b) have developed a new measurement technique with consideration of energy expenditure equations (Garg et al., 1978) and rest allowance formulation (Rohmert, 1973) to simplify the ergonomics assessment of each assembly task. Battini et al. (2015a) have developed functions that are considered warehouse picking activities with the human availability and the rest allowance. Battini et al. (2017a) have developed a new multi-objective model for assembly line balancing, including energy expenditure rate based on Predetermined Motion Energy System (PMES). Battini et al. (2016) have developed a mixed-integer model which integrates assembly line balancing and parts feeding with the incorporation of ergonomic aspects based on rest allowances formulas of Garg et al. (1978) and Price (1990). Andriolo et al. (2016) have developed a lot-sizing model that considers multi-objective optimization of ergonomic aspects based on the lifting index (LI). Battini et al. (2017b) developed a mathematical model that investigates ergonomic lot size, which integrates Price's (1990) rest allowance formulation into the lot-sizing model. They have investigated picking and storing motions with the energy expenditure rate for rest time assessment and did not consider the pushing motion and the maximum endurance time, which has been a key parameter for better ergonomic assessment and calculation of rest time. Botti et al. (2017) have developed a mathematical model to design lean processes with ergonomics for hybrid assembly lines and did not consider the lot size. Three heuristic methods have been developed by Finco et al. (2018), which considers energy expenditure and rest allowance for assembly balancing problems. Finco et al. (2021) have developed a bi-objective model that considers vibration exposure to eliminate ergonomic risks in assembly line design and did not consider the optimal lot size. Al-Araidah et al. (2021) have developed a Monte Carlo simulation model that estimates fatigue allowance (Price, 1990) with the integration of energy expenditure formulas of Garg et al. (1978) for female order pickers. Finco et al. (2020) developed a mathematical model that integrates human energy expenditures in assembly line balancing problems with the smoothness index. The multi-objective mathematical model developed by Zhang et al. (2020) integrates the OCRA method to eliminate the ergonomic risks for U-shaped assembly lines. Their model did not consider finding optimal lot size.

Our investigation of the literature has shown a significant gap regarding maximum endurance time as an ergonomic measure and motions such as pushing, pulling, and so on. Therefore, the aim of the paper at hand is to extend the existing studies and develop a new lot-sizing model for production line supply that covers rest allowance, pushing motion and maximum endurance time for preventing work-related back disorders, and ergonomic risks and supports economic and social sustainability. The objectives of this study are:

1. Extension and development of a new cost model based on relaxation allowance and endurance time formulation, which has been developed by Rohmert $(1960 ; 1973)$.

2. To investigate the effects of endurance time and relaxation allowance with different parameter sets on the total cost of logistics operation.

The model developed in this paper helps to determine the optimal ergonomic total cost of production line supply, to help to reduce ergonomic risks associated with job cycle under study, and to help to increase the overall productivity.

\section{Problem description}

\subsection{Framework of the handling activities and symbols}

The problem and framework studied in this paper is a single material-single operator model, a case of production line supply process, which covers transportation of fixed amount of raw materials from storage plant to production plant by manual material handling with a simple cart. To promote manual handling, transport raw materials and protect the worker from work-related back disorders risks during transportation, the new model investigated specific motions such as lifting, lowering, and pushing during which ergonomic risks may increase. As given in Fig. 1, the 
job cycle consisted of lifting and lowering products to the cart in the raw material storage, transporting raw materials to the supermarket by pushing, loading the raw materials to the supermarket, and moving back with the cart to the raw material storage. Table 1 shows the summarization of symbols and their definition used in the mathematical model.

The following assumptions will be made for developing the new model:

1. The model considered a single worker,

2. A simple cart is used for the transport of the raw materials from the storage to the supermarket for investigation of pushing motion,

3. The model considered a single type of raw material.

\subsection{The AIM methodology}

The AIM tables were invented in the middle of the $1960 \mathrm{~s}$ by Hungarian researchers. AIM tables are used for calculating the time necessity of periodically operating material handling systems. The AIM aims to define the time necessity of a weight forwarding process, the definition of how many machines, tools, workers the system needs, planning the schedule for tasks, and analyzing the working efficiency of existing systems (Barta and Bóna, 2010). The method allowed the planning of systems of material handling by hand without any tools, material handling by hand with tools and forklift trucks. Therefore, we applied the AIM method for defining the material handling time necessities. The applied time estimation procedure in the AIM method is very similar to the well-known MTM (Methods Time Measurement) method, but the AIM method is specialized to logistics activities. The AIM method calculation parameters for production line supply were given in Fig. 2. The $h$ parameters are the levels of the lifting and lowering logistics units from and into the logistics equipment, and the $d$ parameters are the estimated length of the realized moves.
Additionally, we also need to give the weight of the handled logistics units. Based on these parameters, we can calculate the time necessities of the moves.

\section{Mathematical model}

\subsection{Rest allowance and maximum endurance time}

We used the Rohmert (1973) rest time model where the rest time formulation includes endurance time which is the maximum time of load that can be maintained. Based on the formulation developed by Rohmert (1973), the relaxation allowance can be defined as

$T_{R}=1800 \times\left(\frac{t}{T_{E}}\right)^{1.4} \times(f M V C-0.15)^{0.5}$,

where, $T_{R}$ is a rest allowance ( $\%$ of total contraction time); $t$ is a contraction duration (working period of lifting, lowering, or pushing) in a second; $\frac{t}{T_{E}}$ is the relative contraction duration; $T_{E}$ is the endurance time; $f M V C=\frac{f_{\text {load }}}{M V C}$ is the relative force. As given in Fig. 3, the force load on the spine can be determined for lifting, lowering F1, and pushing F3.

Endurance time formulation, which was developed by Rohmert (1960), can be defined as

$T_{E}=-1.5+\frac{2.1}{f M V C}-\frac{0.6}{f M V C^{2}}+\frac{0.1}{f M V C^{3}}$.

According to relaxation formulation, rest time is necessary if $f M V C$ is higher than 0.15 , which leads to $f M V C-0.15 \geq 0$. With this constraint, $T_{R}$ can be expressed by the linear function of the tangent plane approximation (Korkulu, et al., 2021):

$$
T_{R}=A_{r e} \times t+\left(B_{r e} \times f M V C\right)-C_{r e},
$$

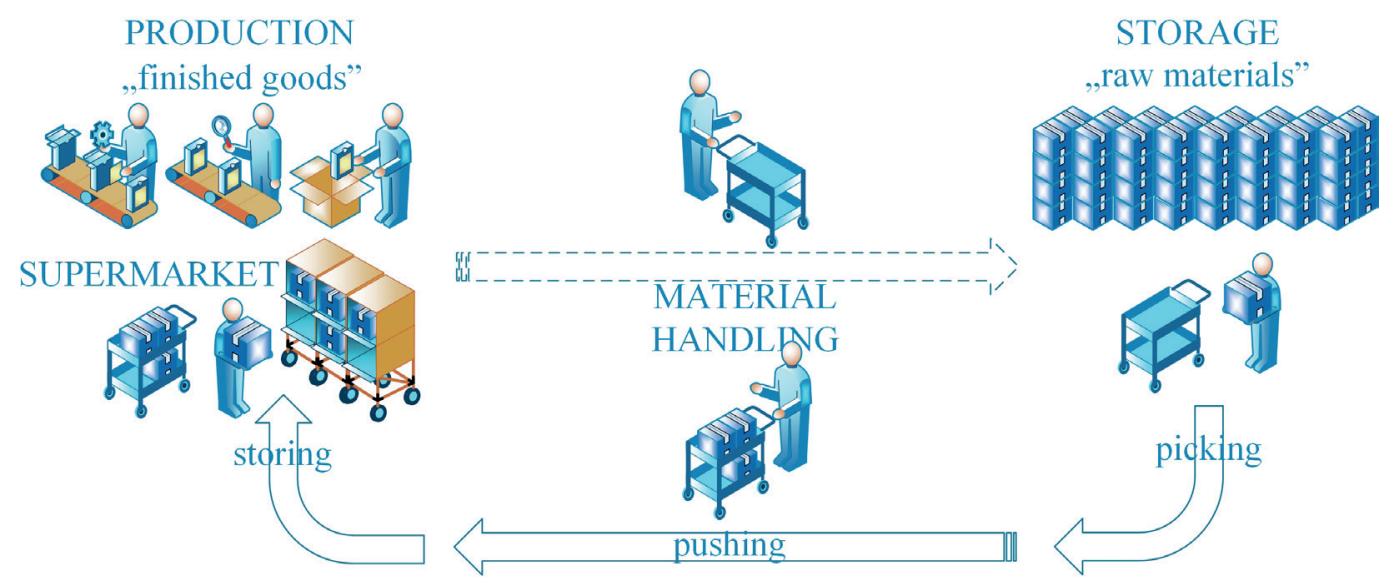

Fig. 1 Job cycle (Single material-single operator model) 
Table 1 Definition and list of symbols

\begin{tabular}{lc}
\hline Symbols & Definition \\
\hline$T_{R}(q)$ & Rest time for avoiding ergonomic risks and disorders \\
occurring from fatigue (min)
\end{tabular}

where $A_{r e}$ is the coefficient of contraction time, $B_{r e}$ is the coefficient of relative force and $C_{r e}$ is the coefficient of the rest time. The linear function of rest time and endurance time can be defined as

$$
T_{R}(q)=3.64 \times t \times q+(32.22 \times f M V C)-5.32 .
$$

We calculated $M V C$ equals $F_{\text {max }}$ related to the investigated activities, which can be defined in the case of picking and storing as

$F_{\max _{p i s t}}=\frac{f_{\text {max }_{p i-s t}} \times g \times b}{a}$,

and in the case of pushing the $F_{\text {max }}$ can be defined as

$$
F_{\max _{p u}}=\frac{f_{\max _{p u}} \times g \times \mu \times d}{c},
$$

where based on Fig. 3, $a$ is the length of the load on the spine; $b$ is the distance from the body axis; $c$ is the height of the load on the spine and load axis; $d$ is the distance between shoulder and waist; $g$ is the gravitational acceleration and $\mu$ is the coefficient of rolling friction. The parameter $f_{\text {max }_{p i s t}}$ is a maximum load value for picking and storing motions calculated according to the standard "ISO 11228-1:2003(en) Ergonomics - Manual handling _ Part 1: Lifting and carrying" (ISO, 2003) limit for two-handed lifting, which is $25 \mathrm{~kg}$. The parameter $f_{\max _{p u}}$ is the maximum load value for pushing calculated as suggested by Resnick and Chaffin (1995), which is the load limit of $225 \mathrm{~kg}$ for four-wheeled carts. To calculate $f M V C_{p i-s t}$, we applied force load of picking and storing, which can be defined as

$$
F_{\text {load }_{p i-s t}}=\frac{q \times w_{u n} \times g \times b}{a},
$$

where $w_{u n}$ is the unit weight of material and $q$ is the lot size, which is equal to a box of materials. To calculate $f M V C_{p u}$, we applied force load of pushing, which can be defined as:

$F_{\text {load }_{p u}}=\frac{\left(\left(\frac{33.75-w_{c}}{3.75}\right) \times q \times w_{u n}+w_{c}\right) \times g \times \mu \times d}{c}$,

where $w_{c}$ is the weight of the cart. $T_{R} \geq 0$ if

$$
f M V C_{p i-s t}(q)=\frac{F_{\text {load }_{p i-s t}}}{F_{\max _{p i-s t}}} \geq 0.15,
$$

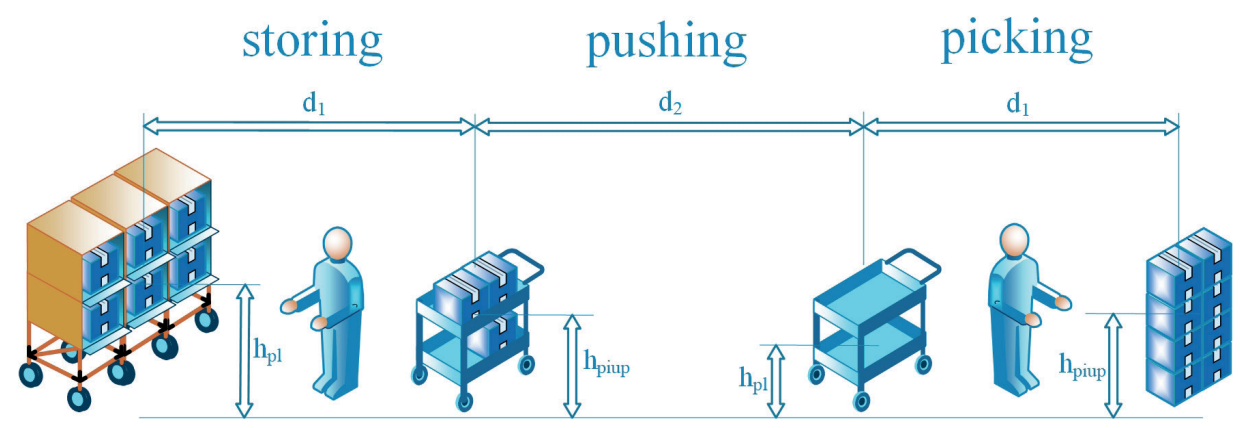

Fig. 2 AIM calculation parameters for the investigated job cycle 


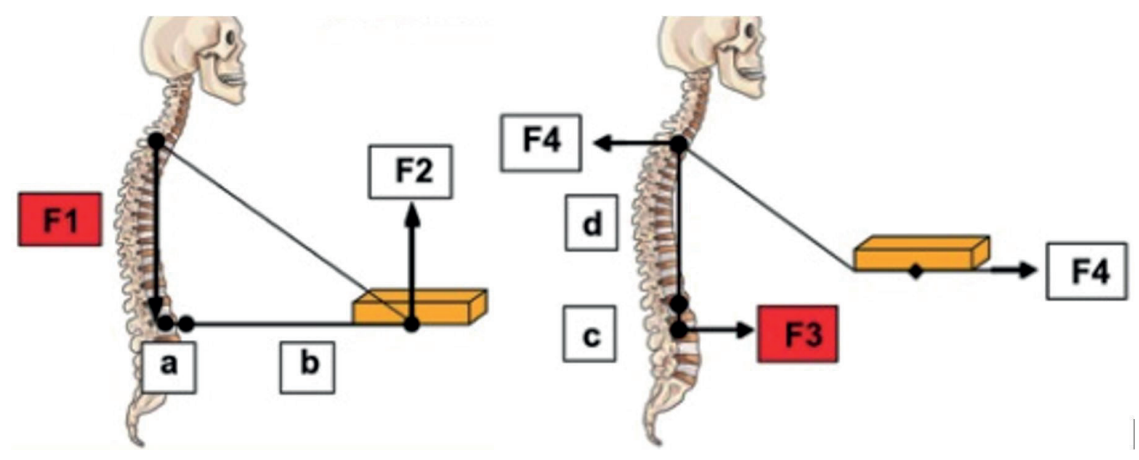

Fig. 3 The load on the spine

and

$$
f M V C_{p u}(q)=\frac{F_{l o a d_{p u}}}{F_{\max _{p u}}} \geq 0.15 .
$$

According to Eq. (9), $\frac{q \times w_{u n}}{25} \geq 0.15$ and therefore $q \times w_{u n} \geq 3.75 \mathrm{~kg}$. According to Eq. (10), and if we introduce the $r=\frac{33.75-w_{c}}{3.75}$ coefficient, then $\quad \frac{\left(r \times q \times w_{u n}+w_{c}\right) \times g \times \mu \times d}{225 \times g \times \mu \times d} \geq 0.15, \quad$ and therefore $\frac{r \times q \times w_{u n}+w_{c}}{225} \geq 0.15$. Therefore, if we consider the maximum limit values for the handled weights, then $r \times q \times w_{u n} \geq 33.75-w_{c}$ must be also met.

\subsection{The extended new model}

In the literature, there can be found few lot sizing and inventory models with ergonomics such as Andriolo et al. (2016); Battini et al. (2014; 2015b; 2016; 2017b). Battini et al. (2017b) have developed a mathematical model which investigates ergonomic lot size for picking and storing motions. We developed and extended the studies in literature (Andriolo et al., 2016; Battini et al., 2016; 2017a) with lifting, lowering, pushing, pushing back, endurance time and rest allowance and inventory cost functions as follows:

$$
\begin{aligned}
& C_{p}(q)=2 \times r \times t_{\text {picking }} \times q \times c_{w} \times\left\lceil\frac{Q}{r \times q}\right\rceil, \\
& C_{s}(q)=2 \times r \times t_{\text {storing }} \times q \times c_{w} \times\left\lceil\frac{Q}{r \times q}\right\rceil, \\
& C_{p u s h}(q)=r \times t_{\text {push }} \times q \times c_{w} \times\left\lceil\frac{Q}{r \times q}\right\rceil,
\end{aligned}
$$

$$
C_{p u s h b}(q)=t_{p u s h b} \times c_{w} \times\left\lceil\frac{Q}{r \times q}\right\rceil,
$$

$C_{T_{R}}(q)=\left(\begin{array}{c}2 \times r \times q \times\left(T_{R_{t_{p}}} \times t_{\text {picking }}+T_{R_{t_{s}}} \times t_{\text {storing }}\right) \\ +T_{R_{t_{\text {push }}}} \times t_{\text {pushb }}+r \times q \times T_{R_{t_{\text {push }}}} \times t_{\text {push }}\end{array}\right) \times c_{w}$

$\times\left\lceil\frac{Q}{r \times q}\right\rceil$,

$C_{I N V}(q)=\frac{t_{a} \times r \times q}{2} \times\left\lceil\frac{Q}{r \times q}\right\rceil \times c_{h}=\frac{t_{a} \times r \times q}{2} \times\left\lceil\frac{T}{t_{a}}\right\rceil \times c_{h}$.

The definition of the total cost function, which includes relaxation allowance cost as follows (Eq. (17)):

$$
\begin{aligned}
& C(q)=C_{I N V}(q)+C_{O P}(q)+C_{T_{R}}(q) \\
& =C_{I N V}(q)+C_{p}(q)+C_{s}(q)+C_{p u s h b}(q)+C_{p u s h}(q)+C_{T_{R}}(q),
\end{aligned}
$$

where $C(q)$ is the total cost of the production line supply, $C_{I N V}(q)$ is the total cost of inventory, $C_{O P}(q)$ is the total cost of logistics operations, $C_{p}(q)$ is the cost of picking, $C_{s}(q)$ is the cost of storing, $C_{\text {push }}(q)$ is the cost of pushing the loaded cart, $C_{\text {pushb }}(q)$ is the cost of back traveling with pushing (empty cart) of the cart and $C_{T_{R}}(q)$ is the cost of relaxation allowance.

Equations (11), (12), and (13) are the cost functions for picking, storing, and pushing motions which represented the total time spent for picking, storing, and pushing the total amount of items and were also multiplied with unit worker wage as a cost of the worker. Equation (14) is the cost function for back traveling to storage with pushing the cart. Equation (15) includes rest time for three activities to prevent any disorders occurring from fatigue. It is also the cost function for rest time which is the total time spent on resting for handling the total amount of items multiplied with unit worker wage. Equation (16) is the cost function of inventory holding. 
The total cost function can be rewritten as

$$
\begin{aligned}
& C(q)=\frac{q \times r \times T}{2} \times c_{h}+\left[2 \times t_{\text {picking }}+2 \times t_{\text {storing }}+t_{\text {push }}+\left[\begin{array}{l}
\left(3.64 \times t_{\text {picking }} \times q+\left(32.22 \times f M V C_{p i-s t}(q)-5.32\right)\right) \times 2 \times t_{\text {picking }} \\
+\left(3.64 \times t_{\text {storing }} \times q+\left(32.22 \times f M V C_{p i-s t}(q)-5.32\right)\right) \times 2 t_{\text {storing }} \\
+\left(3.64 \times r \times t_{\text {push }} \times q+\left(32.22 \times f M V C_{p u}(q)-5.32\right)\right) \times t_{\text {push }}
\end{array}\right] \times Q \times c_{w}\right. \\
& +\left[t_{\text {push }}+\left(\left(3.64 \times t_{\text {push }}+\left(32.22 \times \frac{g \times w_{c} \times d \times \mu}{c \times F_{\text {max }_{p u}}}-5.32\right)\right) \times t_{\text {push }}\right)\right] \times c_{w} \times\left[\frac{Q}{r \times q}\right] .
\end{aligned}
$$

To find the optimal lot size $\left(q^{*}\right)$, the derivation of the total cost function with respect to " $q$ " is calculated as

$$
\begin{aligned}
& \frac{\partial C(q)}{\partial q}=Q \times c_{w} \times\left(C P I+C S T+C P U-C P U B \times \frac{1}{q^{2}}\right) \\
& -C H O=0,
\end{aligned}
$$

where

$$
C P I=2 \times t_{\text {picking }} \times\left(\begin{array}{l}
\frac{3.01 \times 10^{7} \times t_{\text {picking }}}{8.25 \times 10^{6}} \\
+\frac{1.04 \times 10^{8} \times b \times g \times w_{u n}}{3.21 \times 10^{6} \times a \times f_{\max _{\text {pisst }}}}
\end{array}\right),
$$

Eq. (20) called as picking coefficient;

$$
C S T=2 \times t_{\text {storing }} \times\left(\begin{array}{l}
\frac{3.01 \times 10^{7} \times t_{\text {storing }}}{8.25 \times 10^{6}} \\
+\frac{1.04 \times 10^{8} \times b \times g \times w_{\text {un }}}{3.21 \times 10^{6} \times a \times f_{\text {max }_{\text {pist }}}}
\end{array}\right) \text {, }
$$

Eq. (21) called as storing coefficient;

$$
C P U=t_{p u s h} \times\left(\begin{array}{l}
\frac{2.40 \times 10^{7} \times t_{p u s h} \times\left(33.75-w_{c}\right)}{2.48 \times 10^{7}} \\
+\frac{2.76 \times 10^{7} \times d \times g \times \mu \times w_{u n} \times\left(33.75-w_{c}\right)}{3.21 \times 10^{6} \times c \times f_{\max _{p u}}}
\end{array}\right),
$$

Eq. (22) called as pushing coefficient;

$$
C P U B=\frac{15 \times t_{\text {pushb }} \times\left(\begin{array}{l}
\frac{3.01 \times 10^{7} \times t_{\text {pushb }}}{8.25 \times 10^{6}} \\
+\frac{1.04 \times 10^{8} \times d \times g \times \mu \times w_{c}}{3.21 \times 10^{6} \times c \times f_{\text {max }_{p u}}} \\
-\frac{5.78 \times 10^{7}}{1.09 \times 10^{7}}
\end{array}\right)+1}{4 \times\left(33.75-w_{c}\right)},
$$

Eq. (23) called as pushing back coefficient and

$$
C H O=\frac{c_{h} \times\left(4 \times w_{c}-135\right) \times T}{30}
$$

Eq. (24) called as holding coefficient.

Optimal $q^{*}$ after calculation and simplification is defined as

$$
q^{*}=\sqrt{\frac{C P U B}{C P I+C S T+C P U-\frac{C H O}{Q \times c_{w}}}} .
$$

\section{Results}

\subsection{Application of the model and parameter analysis}

To investigate the effects of rest time as a cost, we applied a numerical example, where the total number of items is equal to $2000 \mathrm{pcs}, T$ is equal to $480 \mathrm{~min}$, maximum voluntary contraction $F_{\max _{p i-s t}}$ is equal to $2452.5 \mathrm{~N}$, and it is calculated according to the standard "ISO 11228-1:2003(en) Ergonomics - Manual handling — Part 1: Lifting and carrying" (ISO, 2003) limit for two-handed lifting, which is $25 \mathrm{~kg}$. $F_{\text {max }_{p u}}$ is equal to $4326,5 \mathrm{~N}$, which has been suggested by Resnick and Chaffin (1995) for the load limit of $225 \mathrm{~kg}$ for four-wheeled carts. The cart weight is $25 \mathrm{~kg}$, height of picking up the load is $1.2 \mathrm{~m}$ and $0.2 \mathrm{~m}$, the height of placement of the load is $0.5 \mathrm{~m}$ and $1.2 \mathrm{~m}$, the distance of movement by manual material handling is $2 \mathrm{~m}$ (for picking and storing), the distance of movement by manual material handling is $15 \mathrm{~m}$ (for pushing and pushing back), time need of mounting is $0.50 \mathrm{~min} / \mathrm{pcs}$, unit worker wage is $18 \$ / \mathrm{h}$, inventory holding cost is $0.02 \$ / \mathrm{pcs} / \mathrm{h}$, the weight of each item is $0.3 \mathrm{~kg}, \mu$ is 0.3 . Anthropometric parameters calculated as $a$ and $c$ are $0.05 \mathrm{~m}$ for lifting, lowering, and pushing, $b$ is $0.5 \mathrm{~m}$ for lifting and lowering, and $d$ is $0.35 \mathrm{~m}$ for pushing, according to work-related musculoskeletal disorders journal of Koltan (2007). 
We can calculate the optimal $q^{*}$ of production line supply process for $w_{u n}=0.3 \mathrm{~kg}$ according to Eq. (25), which equals 4 pcs/box. We can also calculate the number of boxes transported with cart for each pushing motion as $r=\frac{33.75-w_{c}}{3.75}=\frac{33.75-25}{3.75} \cong 2$ boxes which is equal to 8 pcs.

The total cost for $q^{*}=4$ pcs equals $C(q)=117.43 \$$ where, $C_{O P}(q)=116.1 \$, C_{I N V}(q)=1.33 \$$ and $C_{T_{R}}(q)=0 \$$.

We compare our result with the total cost of maximum lifting and carrying limit (25 kg) according to the standard "ISO 11228-1:2003(en) Ergonomics - Manual handling - Part 1: Lifting and carrying" (ISO, 2003) for production line supply process under study. The total cost of $q=25$ pcs equals to $25 \mathrm{~kg}$ is $C(q)=206.92 \$$, where $C_{I N V}(q)=28.70 \$, C_{T_{R}}(q)=168.7 \$, C_{O P}(q)=9.51 \$$, and the saving from using our model with ergonomic rest time and maximum endurance time equals $43.2 \%$. The total cost of maximum lifting and carrying limit $(25 \mathrm{~kg})$ is higher as it generates more rest time and a high risk of musculoskeletal disorders.

We calculated the savings obtained by using our new approach with different $w_{u n}(0.05 \mathrm{~kg}, 0.06 \mathrm{~kg}, 0.07 \mathrm{~kg}$, $0.08 \mathrm{~kg}, 0.09 \mathrm{~kg}, 0.1 \mathrm{~kg}, 0.2 \mathrm{~kg}, 0.3 \mathrm{~kg}, 0.4 \mathrm{~kg}, 0.5 \mathrm{~kg}$, $0.6 \mathrm{~kg}, 0.7 \mathrm{~kg}, 0.8 \mathrm{~kg}, 0.9 \mathrm{~kg}, 1 \mathrm{~kg}, 1.1 \mathrm{~kg}, 1.2 \mathrm{~kg}, 1.3 \mathrm{~kg}$, $1.4 \mathrm{~kg}, 1.5 \mathrm{~kg}, 1.6 \mathrm{~kg}, 1.7 \mathrm{~kg}, 1.8 \mathrm{~kg}, 1.9 \mathrm{~kg}$ and $2 \mathrm{~kg}$ ) and savings were calculated comparing the total cost of maximum lifting and carrying limit $(25 \mathrm{~kg})$ according to the standard "ISO 11228-1:2003(en) Ergonomics - Manual handling - Part 1: Lifting and carrying" (ISO, 2003) limit for two-handed lifting where each lot size $\mathrm{kg}$ value equals $25 \mathrm{~kg}$. As given in Fig. 4, an increase in unit weight reduced the optimal lot size and total cost and increased the savings. An increase in unit weight will increase the relative force of

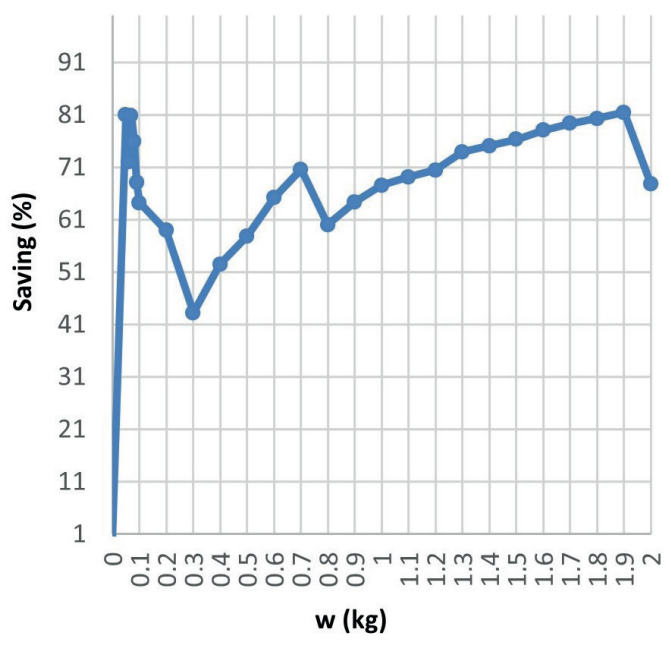

Fig. 4 Savings for different weights of each item the muscle for handling. Therefore, handling heavier items will increase the rest time needs of the worker, and it leads to higher rest time costs. Our model suggests decreasing lot size for heavier items to optimize rest time cost and ergonomic risk. Therefore, our extended new model optimizes both economic and ergonomic aspects of the specific production process investigated under this study.

We calculated the optimal lot sizes for different unit weights $(0.01 \mathrm{~kg}, 0.02 \mathrm{~kg}, 0.03 \mathrm{~kg}, 0.04 \mathrm{~kg}, 0.05 \mathrm{~kg}, 0.06 \mathrm{~kg}$, $0.07 \mathrm{~kg}, 0.08 \mathrm{~kg}, 0.09 \mathrm{~kg}, 0.1 \mathrm{~kg}, 0.2 \mathrm{~kg}, 0.3 \mathrm{~kg}, 0.4 \mathrm{~kg}$, $0.5 \mathrm{~kg}, 0.6 \mathrm{~kg}, 0.7 \mathrm{~kg}, 0.8 \mathrm{~kg}, 0.9 \mathrm{~kg}, 1 \mathrm{~kg}, 1.1 \mathrm{~kg}, 1.2 \mathrm{~kg}$, $1.3 \mathrm{~kg}, 1.4 \mathrm{~kg}, 1.5 \mathrm{~kg}, 1.6 \mathrm{~kg}, 1.7 \mathrm{~kg}, 1.8 \mathrm{~kg}, 1.9 \mathrm{~kg}$ and $2 \mathrm{~kg}$ ) with our new model. As given in Fig. 5, the increase in unit weight of the item reduces the optimal lot size value. The reason for this is that the relative force $(f M V C)$ is calculated according to unit item weight as we explained earlier in Subsection 3.1, therefore, increase in weight value decreases the lot size for reducing ergonomic risks.

We analyzed the model under different parameter values to determine how total, operational, inventory, relaxation time cost changes. We applied three different item weights, which are $0.25 \mathrm{~kg}, 0.5 \mathrm{~kg}$, and $1 \mathrm{~kg}$, and other parameters were constant, cart weight is $25 \mathrm{~kg}$, unit storing time is changing between $0.13-0.20 \mathrm{~min}$, unit picking time is changing between $0.13-0.20 \mathrm{~min}$, unit pushing time is changing between $0.21-0.28 \mathrm{~min}$ and pushing back time is equal to $0.14 \mathrm{~min}$, unit worker wage is equal to $18 \$ / \mathrm{h}$, inventory holding cost is $0.02 \$ / \mathrm{pcs} / \mathrm{h}, a$ and $c$ are $0.05 \mathrm{~m}$ for lifting, lowering and pushing, $b$ is $0.5 \mathrm{~m}$ for picking and storing, and $d$ is $0.35 \mathrm{~m}$ for pushing, $\mu$ is 0.3 .

Results of the analysis were given in Fig. 6, Fig. 7, and Fig. 8, which illustrate that an increase in weight of the item will increase, especially the total cost and cost of rest

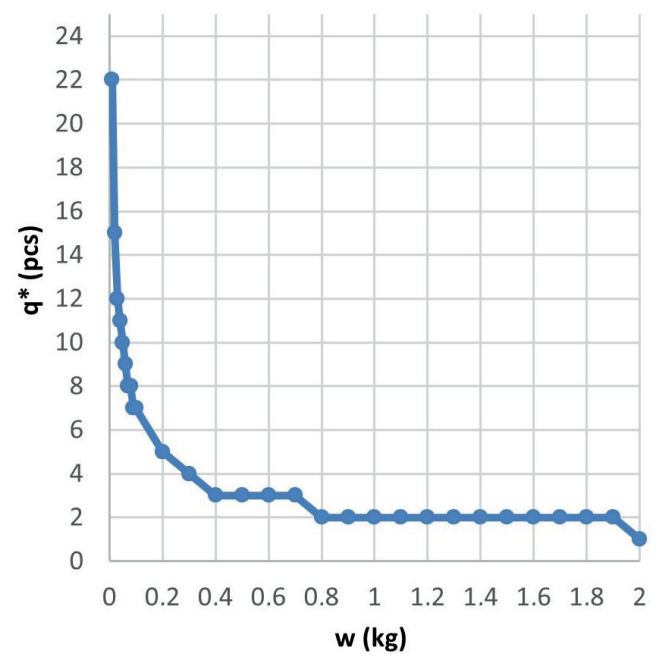

Fig. 5 Optimal lot size $(q)$ for different weights of each item 


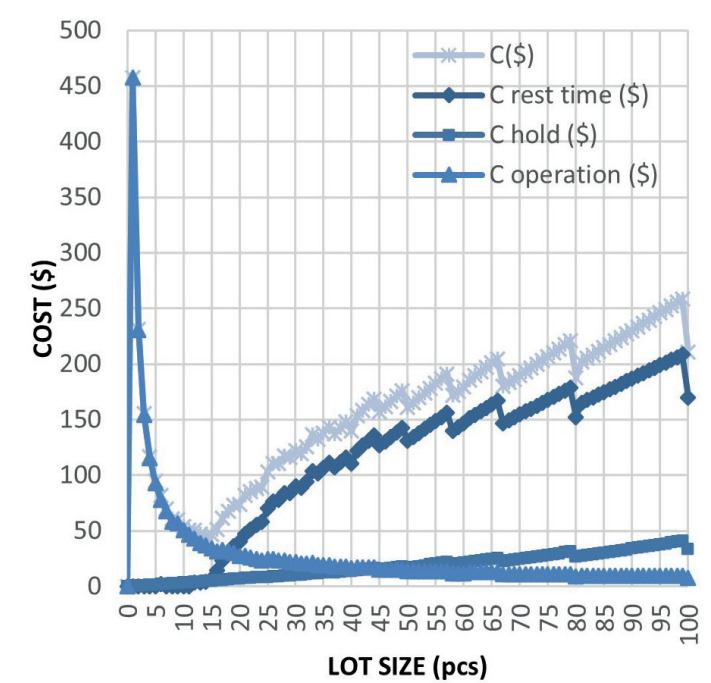

Fig. 6 Total cost curve, rest time cost, holding cost and operational cost curves for alternative lot size $\left(w_{u n}=0.25 \mathrm{~kg}\right)$

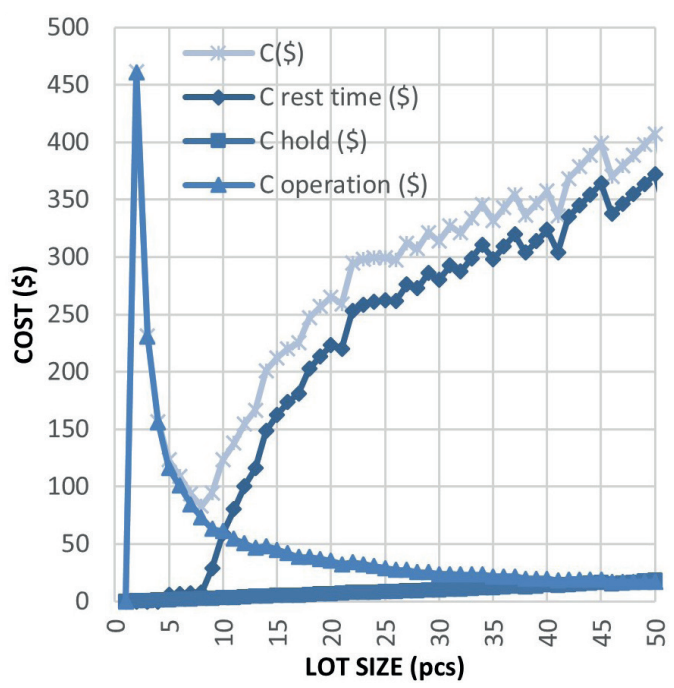

Fig. 7 Total cost curve, rest time cost, holding cost, and operational cost curves for alternative lot size $\left(w_{u n}=0.5 \mathrm{~kg}\right)$

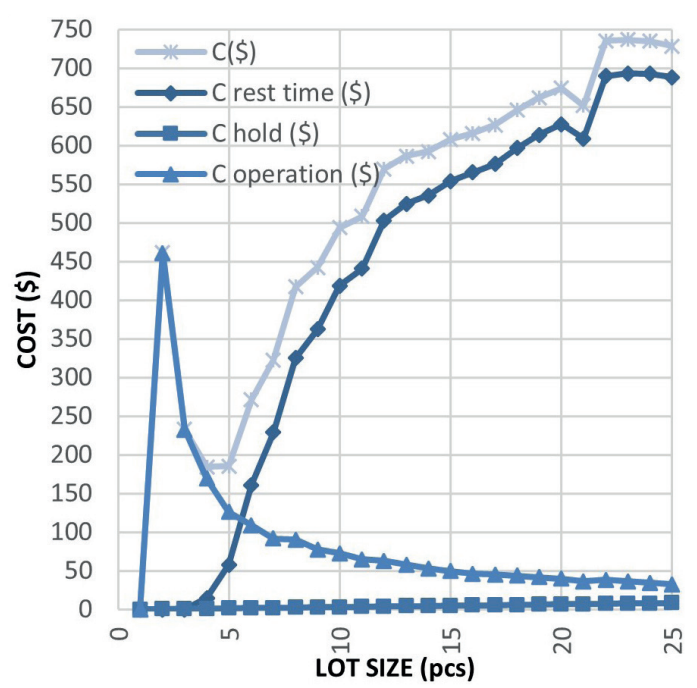

Fig. 8 Total cost curve, rest time cost, holding cost, and operational cost curves for alternative lot size $\left(w_{u n}=1 \mathrm{~kg}\right)$ time, and decrease the $q^{*}$. In particular, there is no big difference between the operational cost and inventory cost when the weight of the item changes. As can be seen, the optimal solutions suggested by the model lower the weight of the item or decrease the lot size in order to decrease the total cost and the rest time cost.

We applied different distance values for lifting, lowering, and pushing motions between the storage and supermarket of the production line area for analysis. The distance values changed for $d_{1}$ between 15 to $1 \mathrm{~m}$ and unit item weight of the material are equal to $0.25,0.50$ and $1 \mathrm{~kg}$. As given in Fig. 9, an increase in distance $d_{1}$ increases the rest time need and rest time cost. Furthermore, an increase in item weight increases the rest time cost.

We applied different distance values to analyze the pushing motion between the storage and supermarket of the production line. The distance value of $d_{2}$ changes between 400 to $5 \mathrm{~m}$. The unit item weights of the material are equal to $0.25,0.50$, and $1 \mathrm{~kg}$. Fig. 10 illustrates that the increase in distance of $d_{2}$ will increase the rest times and rest time costs. Furthermore, an increase in distance $d_{2}$ will increase rest time costs more for heavier items as an increase in weight will increase the relative force and time of handling.

\section{Conclusion and further research}

The work-related musculoskeletal disorders and work-related back disorders are the most common health problems in the World. Especially, manual handling, uncomfortable working positions and repetitive movements, all actions which are often associated with working in a manual job are the most common causes of musculoskeletal disorders. Although many research studies have contributed on the

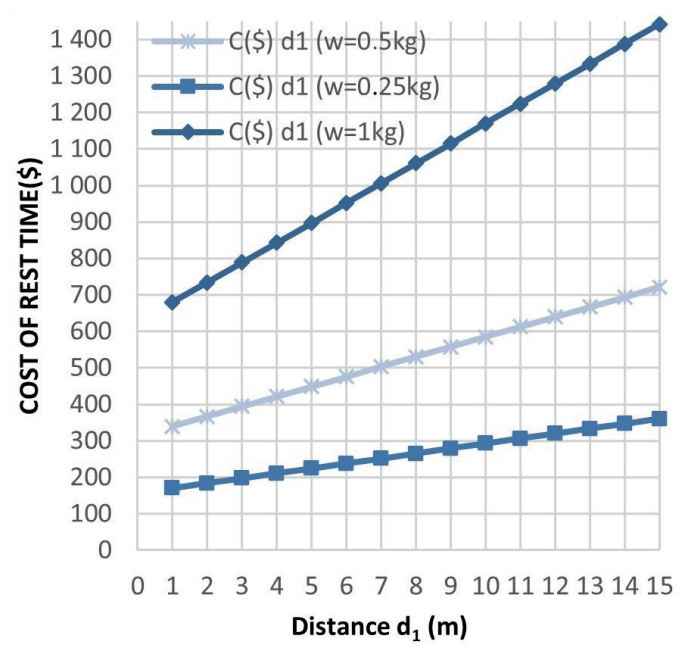

Fig. 9 The rest time cost for different distances of transportation of lifting and lowering $\left(d_{1}\right)$ 


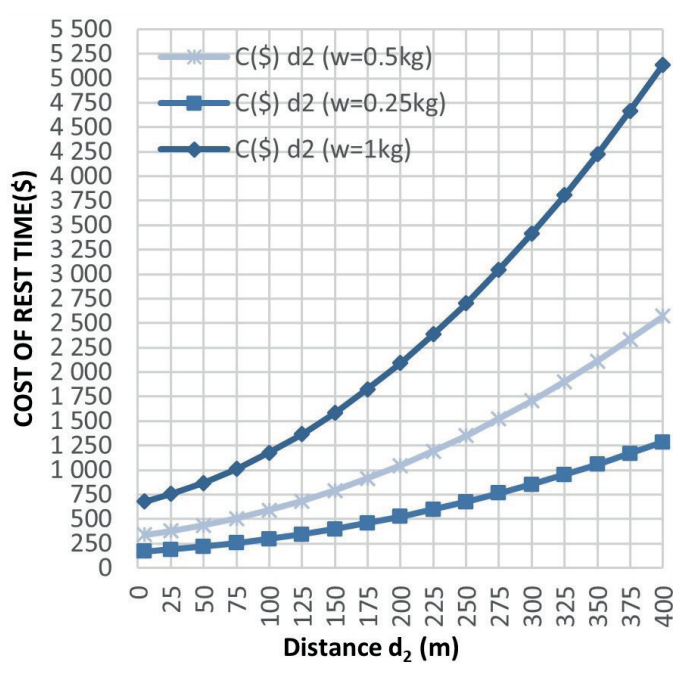

Fig. 10 The rest time cost for different distances of storage and supermarket of the production line $\left(d_{2}\right)$

lot sizing, work-related back disorders and ergonomics in lot sizing has received very little attention in the literature so far. In this paper, in order to improve ergonomic conditions and to reduce the risk of work-related back disorders, the ergonomics aspects were integrated into lot

\section{References}

Al-Araidah, O., Okudan-Kremer, G., Gunay, E. E., Chu, C. Y. (2021) "A Monte Carlo simulation to estimate fatigue allowance for female order pickers in high traffic manual picking systems", International Journal of Production Research, 59(15), pp. 4711-4722. https://doi.org/10.1080/00207543.2020.1770357

Andriolo, A., Battini, D., Persona, A., Sgarbossa, F. (2016) "A new bi-objective approach for including ergonomic principles into EOQ model", International Journal of Production Research, 54(9), pp. 2610-2627.

https://doi.org/10.1080/00207543.2015.1113324

Barta, Z., Bóna, K. (2010) "Development of AIM Method Planning of Inbound Material Handling Processes", Acta Technica Jaurinensis, 3(3), pp. 285-299. [online] Available at: https://acta.sze.hu/index. php/acta/article/view/79 [Accessed: 12 February 2020]

Battini, D., Faccio, M., Persona, A., Sgarbossa, F. (2011) "New methodological framework to improve productivity and ergonomics in assembly system design", International Journal of Industrial Ergonomics, 41(1), pp. 30-42.

https://doi.org/10.1016/j.ergon.2010.12.001

Battini, D. Persona, A. Sgarbossa, F. (2014) "A sustainable EOQ model: Theoretical formulation and applications", International Journal of Production Economics, 149, pp. 145-153. https://doi.org/10.1016/j.ijpe.2013.06.026

Battini, D., Calzavara, M., Persona, A., Sgarbossa, F. (2015a) "Linking human availability and ergonomics parameters in order-picking systems", IFAC-PapersOnLine, 48(3), pp. 345-350. https://doi.org/10.1016/j.ifacol.2015.06.105 sizing in a new extended lot-sizing model. The developed model analysis results showed that the developed method provides notable advantages as it increases overall productivity using the rest allowance concept with maximum endurance time. The integrated model can help to reduce the ergonomic risks regarding to work-related back disorders resulting from manual handling work and improve ergonomics aspect in industrial practices and promote both economic and social sustainability.

The model proposed in this paper investigated the supplying process of one kind of raw material with one operator to the production line with a simple cart and future work could investigate first, a situation with handling more raw materials as multi material-single operator and multi material-multi operator to improve the ergonomic conditions and social sustainability in industrial practices. Furthermore, investigation in the handling of materials in semi-automated production line where the repetitive motion and force of movement increase the risk of the work-related back disorders and ergonomic risks, would be valuable extension of these research topics.

Battini, D., Glock, C. H., Grosse, E. H., Persona, A., Sgarbossa, F. (2015b) "Ergo-Lot-Sizing: Considering Ergonomics in Lot-Sizing Decisions", IFAC-PapersOnline, 48(3), pp. 326-331. https://doi.org/10.1016/j.ifacol.2015.06.102

Battini, D., Calzavara, M., Otto, A., Sgarbossa, F. (2016) "The Integrated Assembly Line Balancing and Parts Feeding Problem with Ergonomics Considerations", IFAC-PapersOnLine, 49(12), pp. 191-196. https://doi.org/10.1016/j.ifacol.2016.07.594

Battini, D., Calzavara, M., Otto, A., Sgarbossa, F. (2017a) "Preventing ergonomic risks with integrated planning on assembly line balancing and parts feeding", International Journal of Production Research, 55(24), pp. 7452-7472. https://doi.org/10.1080/00207543.2017.1363427

Battini, D., Glock, H. C., Grosse, E. H., Persona, A., Sgarbossa, F. (2017b) "Ergo-lot-sizing: An approach to integrate ergonomic and economic objectives in manual materials handling", International Journal of Production Economics, 185, pp. 230-239. https://doi.org/10.1016/j.ijpe.2017.01.010

Botti, L., Mora, C., Regattieri, A. (2017) "Integrating ergonomics and lean manufacturing principles in a hybrid assembly line", Computers \& Industrial Engineering, 111, pp. 481-491. https://doi.org/10.1016/j.cie.2017.05.011

Ciccullo, F., Pero, M., Caridi, M., Gosling, J., Purvis, L. (2018) "Integrating the environmental and social sustainability pillars into the lean and agile supply chain management paradigms: A literature review and future research directions", Journal of Cleaner Production, 172, pp. 2336-2350. https://doi.org/10.1016/j.jclepro.2017.11.176 
Corlett, E. N., Manenica, I. (1980) "The effects and measurement of working postures", Applied Ergonomics, 11(1), pp. 7-16. https://doi.org/10.1016/0003-6870(80)90115-5

Cunha, L. R. A., Delfino, A. P. S., dos Reis, K. A., Leiras, A. (2018) "Economic production quantity (EPQ) model with partial backordering and a discount for imperfect quality batches", International Journal of Production Research, 56(18), pp. 6279-6293. https://doi.org/10.1080/00207543.2018.1445878

Eksioglu, M. (2011) "Endurance time of grip-force as a function of gripspan, posture and anthropometric variables", International Journal of Industrial Ergonomics, 41(5), pp. 401-409. https://doi.org/10.1016/j.ergon.2011.05.006

EU-OSHA (2017) "An international comparison of the cost of work-related accidents and illnesses", European Agency for Safety and Health at Work, pp. 1-8. [online] Available at: https://osha.europa.eu/en/toolsand-publications/publications/international-comparison-cost-workrelated-accidents-and/view [Accessed: 10 December 2021]

Finco, S., Battini, D., Delorme, X., Persona, A., Sgarbossa, F. (2018) "Heuristic methods to consider rest allowance into assembly balancing problem", IFAC-PapersOnLine, 51(11), pp. 669-674. https://doi.org/10.1016/j.ifacol.2018.08.395

Finco, S., Battini, D., Delorme, X., Persona, A., Sgarbossa F. (2020) "Workers' rest allowance and smoothing of the workload in assembly lines", International Journal of Production Research, 58(4), pp. $1255-1270$. https://doi.org/10.1080/00207543.2019.1616847

Finco, S., Abdous, M. A., Calzavara, M., Battini, D., Delorme, X. (2021) "A bi-objective model to include workers' vibration exposure in assembly line design", 59(13), pp. 4017-4032. https://doi.org/10.1080/00207543.2020.1756512

Garg, A., Chaffin, D. B., Herrin, G. D. (1978) "Prediction of metabolic rates for manual materials handling jobs", The American Industrial Hygiene Association Journal, 39(8), pp. 661-674 https://doi.org/10.1080/0002889778507831

Garg, A., Hegmann, K. T., Schwoerer, B. J., Kapellusch, J. M. (2002) "The effect of maximum voluntary contraction on endurance times for the shoulder girdle", International Journal of Industrial Ergonomics, 30(2), pp. 103-111.

https://doi.org/10.1016/S0169-8141(02)00078-1

Ghare, P., Schrader, G. (1963) "A model for Exponentially decaying inventory system", International Journal of Production and Research, 21, pp. 449-460.

Goyal, S. K. (1985) "Economic Order Quantity Under Conditions of Permissible Delay in Payments", Journal of the Operational Research Society, 36(4), pp. 335-338.

https://doi.org/10.2307/2582421

Hadley, G., Whitin, T. M. (1963) "Analysis of inventory systems", Prentice-Hall, Englewood Cliffs, NJ, USA.

International Organization for Standardization (2003) "ISO 112281:2003(en) Ergonomics - Manual handling - Part 1: Lifting and carrying", International Organization for Standardization, Geneva, Switzerland. [online] Available at: https://www.iso.org/obp/ ui/\#iso:std:iso:11228:-1:ed-1:v1:en [Accessed: 15 February 2020]

Korkulu, S., Bóna, K. (2019) "Ergonomics as a Social Component of Sustainable Lot-sizing: A Review", Periodica Polytechnica Social and Management Sciences, 27(1), pp. 1-8. https://doi.org/10.3311/PPso.12286
Korkulu, S., Bóna, K., Péter, T. (2021) "Developing a Model with Ergonomic Aspects Using Endurance Time and Rest Allowance for Supporting the Optimization of Production Line Material Supply: A Case of Single-Operator Multi-Materials", Mathematical Problems in Engineering, 2021, Article ID: 9957299. https://doi.org/10.1155/2021/9957299

Koltan, A. (2007) "Mesleki Kas İskelet Sistemi Hastaliklarini Önlemede Bir Ergonomik Yaklaşim Modeli" (Ergonomic model that helps to prevent work-related musculoskeletal disorders), Occupational Health and Safety Journal, Ministry of Labor and Social Security of Turkey, 34(7), pp. 37-45 [online] Available at: https://www.csgb.gov. tr/isggm/dergiler/34.pdf [Accessed: 21 February 2017] (in Turkish)

Price, A. D. F. (1990) "Calculating relaxation allowances for construction operatives - Part 1: Metabolic cost", Applied Ergonomics, 21(4), pp. 311-317.

https://doi.org/10.1016/0003-6870(90)90202-9

Rezaei, J. (2014) "Economic order quantity for growing items", International Journal of Production Economics, 155, pp. 109-113. https://doi.org/10.1016/j.ijpe.2013.11.026

Resnick, M. L., Chaffin, D. B. (1995) "An ergonomic evaluation of handle height and load in maximal and submaximal cart pushing", Applied Ergonomics, 26(3), pp. 173-178. https://doi.org/10.1016/0003-6870(95)00014-4

Rohmert, W. (1960) "Ermittlung von Erholungspausen für Statische Arbeit des Menschen" (Determination of recovery breaks in case of human static work), Internationale Zeitschrift für angewandte Physiologie einschließlich Arbeitsphysiologie, 18(2), pp. 123-164. (in German) https://doi.org/10.1007/BF00698869

Rohmert, W. (1973) "Problems in determining rest allowances: Part 1: Use of modern methods to evaluate stress and strain in static muscular work", Applied Ergonomics, 4(2), pp. 91-95. https://doi.org/10.1016/0003-6870(73)90082-3

Rohmert, W., Wangenheim, M., Mainzer, J., Zipp, P., Lesser, W. (1986) "A study stressing the need for a static postural force model for work analysis", Ergonomics, 29(10), pp. 1235-1249. https://doi.org/10.1080/00140138608967237

Rose, L., Örtengren, R., Ericsson, M. (2001) "Endurance, pain in fully flexed postures", Applied Ergonomics, 32(5), pp. 501-508. https://doi.org/10.1016/S0003-6870(01)00016-3

Safaeian, M., Fathollahi-Fard, A. M., Tian, G., Li, Z., Ke, H. (2019) "A multi-objective supplier selection and order allocation through incremental discount in a fuzzy environment", Journal of Intelligent \& Fuzzy Systems, 37(1), pp. 1435-1455. https://doi.org/10.3233/JIFS-182843

Salameh, M. K., Jaber, M. Y. (2000) "Economic production quantity model for items with imperfect quality", International Journal of Production Economics, 64(1-3), pp. 59-64. https://doi.org/10.1016/S0925-5273(99)00044-4

Tiwari, S., Daryanto, Y., Wee, H. M. (2018) "Sustainable inventory management with deteriorating and imperfect quality items considering carbon emission", Journal of Cleaner Production, 192 pp. 281-292. https://doi.org/10.1016/j.jclepro.2018.04.261

Wangsa, D. I., Wee, H. M. (2018) "An integrated vendor-buyer inventory model with transportation cost and stochastic demand", International Journal of Systems Science: Operations \& Logistics, 5(4), pp. 295-309. https://doi.org/10.1080/23302674.2017.1296601 
Zhang, Z., Tang, Q., Ruiz, R., Zhang, L. (2020) "Ergonomic risk and cycle time minimization for the U-shaped worker assignment assembly line balancing problem: A multi-objective approach", Computers \& Operations Research, 118, Article number: 104905. https://doi.org/10.1016/j.cor.2020.104905
Zhao, Q. H., Wang, S. Y., Lai, K. K., Xia, G. P. (2004) "Model and algorithm of an inventory problem with the consideration of transportation cost", Computers \& Industrial Engineering, 46(2), pp. 389-397.

https://doi.org/10.1016/j.cie.2003.12.019 